\title{
Basic study on combustion characteristics of waste rice husk and emission behavior from a new-type air vortex current combustor
}

\author{
Q. Wang ${ }^{1}$, T. Maezono ${ }^{1}$, Q. Chen ${ }^{1}$, P. Apaer ${ }^{1}$, Y. Wang ${ }^{1}$, L. Gui ${ }^{1}$, \\ D. Niida ${ }^{1}$, N. Mitsumura ${ }^{1}$, M. Domon ${ }^{2}$, I. Fujiwara ${ }^{2}$ \\ \& N. Yamaguchi ${ }^{2}$ \\ ${ }^{1}$ Department of Environmental Science and Technology, \\ Graduate School of Science and Engineering, Saitama University, Japan \\ ${ }^{2}$ Kaneko Agricultural Machinery Co, Ltd., Japan
}

\begin{abstract}
There are large quantities of rice husk estimated around 3 million tons as agricultural waste every year in Japan. Air pollutants emitted from exhaust gases of rice husk incineration lead to very important environmental damage, not only because of the influence on global environment and climate, when released into the atmosphere, but also on human health due to the local air pollution. Therefore, it is necessary to effectively utilize the rice husk waste and to reduce the air pollution. We try to develop a new-type air vortex current small-scale combustor which can effectively combust rice husk as biomass energy instead of fossil oil fuel for farming-greenhouses heating during the winter season. In this study, we investigated if rice husk can be fed on the new-type air vortex current small-scale combustor and reduced fossil fuel. The new-type small-scale combustor is able to keep a constant high temperature (about $1000^{\circ} \mathrm{C}$ ) even if the rice husk combustion is not under the best conditions.

At the same time, it is also important to evaluate the emission behavior of harmful air pollutants emitted from the rice husk combustion with measuring carbonaceous and ionic composition of suspended particulate matter (SPM) in the exhaust gases from the new-type air vortex current combustor, and to reduce the pollutant emission by controlling the combustion conditions. From the analytical results of the size distribution of carbonaceous composition collected by an air sampler, it is shown that elemental carbon dominated in the coarse
\end{abstract}


particles, which are produced by incomplete combustion, and organic carbon dominated in the fine particles. Carbonaceous concentrations can be reduced substantially in the emitted particles by highly effective combustion when the combustor was improved. As the results of the ionic composition, high concentrations of potassium ion as a tracer of biomass burning were determined. Combustion temperature control is important to avoid corrosion in the system and the health effects from high concentrations of chloride contents.

Although the new-type air vortex current combustor developed in our purpose is typically small-scale, however, usual fixed-bed combustors are prone to be incomplete because of the simplicity of the structure. Since there are no specific regulations for these kinds of combustors in Japan, therefore, even small combustor fall out of the possibly applicable emissions regulations, to ensure stable combustion performance and less air pollutants. In near future, we try to improve the combustor fed with less fossil oil fuel and more rice husk waste which will be feasible and sustainable.

Keywords: rice husk, combustion characteristics, small-scale combustor, air vortex current, exhaust gases, suspended particulate matter (SPM), carbonaceous and ionic analysis.

\section{Introduction}

Currently, global warming is become increasingly evident in the global climate. Combustion of fossil fuel is generally admitted as the main responsible for global warming. Though, the use of fossil fuel is expected to increase in the future because of economic development and growth of population in developing countries [1], hence, the only solution is zero-emission technology, that is, to reduce and minimalize all possible emissions produced by human activities [2]. In order to achieve zero-emissions, it is important to apply a technology to utilize all unused waste biomass $[3,4]$.

In Japan, waste biomass and residues produced from agricultural and forestry activities have been unused and mostly being incinerated for disposal, due to its high cost of collection, transport, and storage and also the needs of energy that it implies. Moreover, urgent measures are required to reduce the effects to air pollution from illegal incineration.

It is estimated that around 3 million tons of waste rice husk which is the most common agricultural residue are wasted every year in Japan. Additionally, since rice is the staple food and regular part of the diet for almost half of the world population, an effective utilization of waste rice husk will be an important countermeasure to global warming. For these reasons, in the recent years, there is an increasing demand on the utilization of unused biomass instead of usual fossil oil fuel combustors for farming-greenhouses heating during the winter season. This increase in the demand will make prices to increase. In general, these combustors are small-scale [5], therefore, the established regulations (e.g. Japanese air pollution control act and waste disposal and public sanitation regulation) cannot apply for this kind of pollution emission control. So far, small-scale combustors are characterized by simplicity on their structure and low 
cost and hence emit visible black smoke due to their low combustion performance because of the lack of the regulations $[6,7]$.

In this study, we investigated if fossil fuel can be substituted by a new-type air vortex current small-scale combustor of the waste rice husk. This new-type combustor is shown in figure 1. In order to use the waste rice husk samples as the fuel in the new-type air vortex current combustor, we analyzed the chemical composition of the waste rice husk as agricultural waste and investigated its combustion characteristics. Also harmful substances emitted from the rice husk combustion were evaluated by measuring the suspended particulate matter composition on the exhaust, and the reduction possibility of these harmful substances by controlling the combustion conditions was examined.

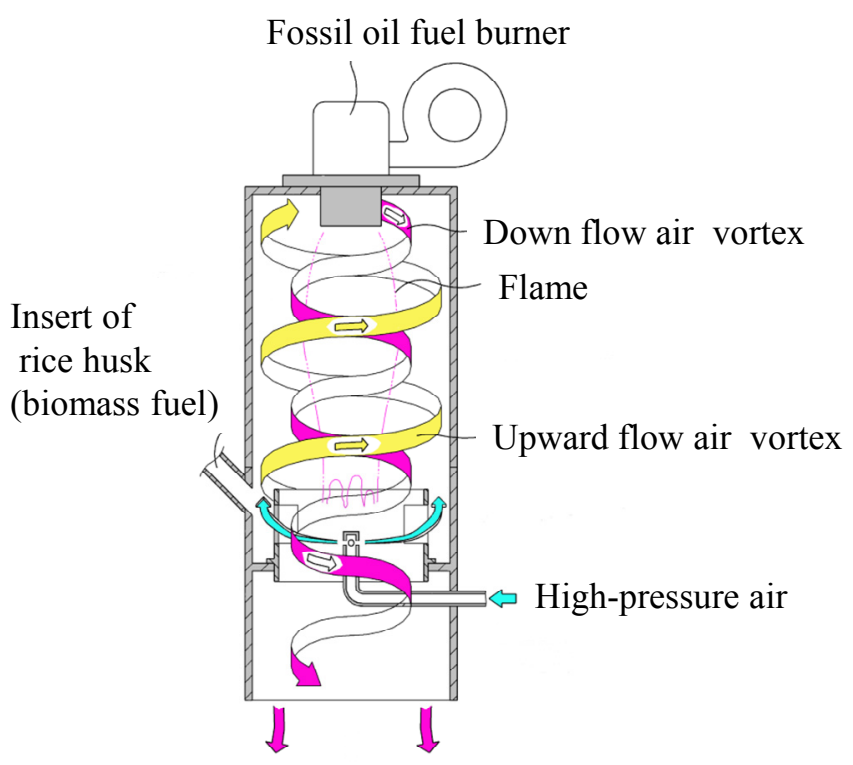

Figure 1: Concept of the new-type air vortex current small-scale combustor.

\section{Experimental methods}

\subsection{Composition analysis of rice husk samples as agricultural waste}

In this study, six different rice husk varieties were analyzed. The proximate and ultimate analyses of rice husk samples from different producing areas (brands and farms) were carried out according to the Japanese industrial standard (JIS) method of JIS-M8812.

\subsection{Evaluation method for combustion of the waste rice husk samples}

Combustion characteristics of rice husk samples from different producing areas were analyzed by the thermogravimetric/differential thermal (pyrolysis) analysis 
(TG/DTA), and under the following conditions: about $1.0 \mathrm{mg}$ of sample was heated at a rate of $5{ }^{\circ} \mathrm{C} \mathrm{min}{ }^{-1}$ starting from room temperature until $600{ }^{\circ} \mathrm{C}$. The

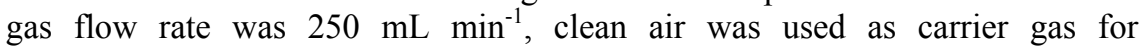
combustion.

\subsection{Combustion control method}

A high temperature resistant cylindrical small-scale combustor with a diameter of $20 \mathrm{~cm}$ was set up. A fossil oil fuel burner was set in the upper side while the waste rice husk was fed in the lower part. The combustion was started first with oil fuel alone and the rice husk was supplied when the reactor wall reached a temperature over $480{ }^{\circ} \mathrm{C}$. Combustion temperature was monitored with a thermocouple and controlled by the supplied air flow rate. The fossil oil fuel supply was stopped when the small-scale combustor wall reached a temperature around $550{ }^{\circ} \mathrm{C}$ and combustion was maintained only by the supply of the waste rice husk samples.

\subsection{Evaluation of suspended particulate matter (SPM) in exhaust gases}

\subsubsection{Air sampling method for exhaust gases collection}

The air sampling system of exhaust gases is shown in figure 2. In order to evaluate the suspended particulate matter (SPM) emitted from the combustor, SPM were collected on quartz-fiber filters $(80 \mathrm{~mm}$ diameter, pallflex prpducts corp, 2500QAT-UP) and Teflon filters (8 mm diameter, pallflex prpducts corp, TX40HI20-WW) using two air samplers which are called the low pressure impactor (LPI: Model LP-20, Tokyo Dylec Corporation).

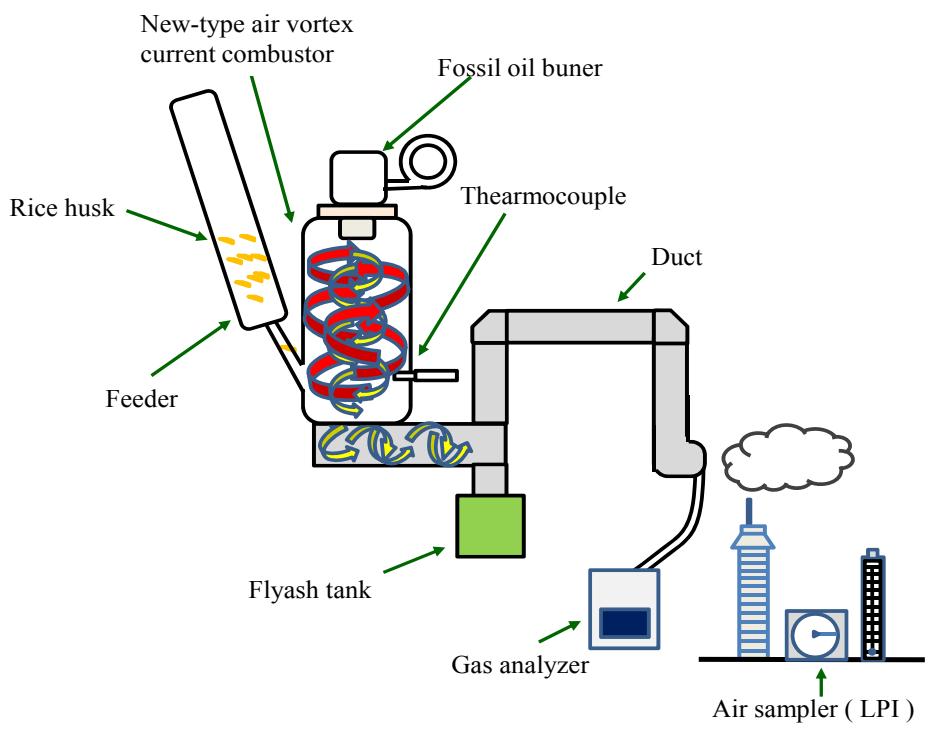

Figure 2: Air sampling method for exhaust gases emitted from the combustor. 
Suspended particulate matter (SPM, separated particle sizes $<0.06,0.06-0.12$, $0.12-0.20,0.20-0.30,0.30-0.50,0.50-0.70,0.70-1.20,1.2-2.1$ and $2.1-3.5 \mu \mathrm{m})$ were collected respectively at a flow rate of $23.6 \mathrm{~L} \mathrm{~min}^{-1}$ for $20 \mathrm{~min}$ on each sampling with LPI air samplers. The quartz-fiber filter samples were used for carbonaceous composition analysis and samples, and the Teflon filters were used for ionic composition analysis. Size distribution, characteristics and chemical components of SPM were measured because of the influence on global environment and climate, when released into the atmosphere, but also on human health due to the local air pollution.

\subsubsection{Evaluation of carbonaceous composition of SPM in the exhaust gases} In generally, coarse particles of suspended particulate matter (SPM) are mainly having a diameter over $2 \mu \mathrm{m}$ and it unable to instruction in to entering the respiratory tract by the nose, throat, and pharynges. However, fine particles with a diameter under $2 \mu \mathrm{m}$ are able to reach deeper parts of the respiratory system, including the air sacs of the lungs. While particles with a diameter below $0.1 \mu \mathrm{m}$ (or ultra fine particles) are able to break into the alveoli and through the capillary beds reach the blood stream. That suspended particulate matter is formed by carbonaceous material. Therefore it is necessary to analyze the size distribution of carbonaceous composition emitted from the combustion of rice husk. Carbonaceous analysis for elemental carbon (EC) and organic carbon (OC) was based on the IMPROVE method (Interagency Monitoring of Protected Visual Environment) by the thermo-optical carbon analyzer (Model 2001, Thermo/Optical Carbon Analyzer, Desert Research Institute) shown in table 1.

In this method, a $0.503 \mathrm{~cm}^{2}(8 \mathrm{~mm}$ diameter) punch aliquot of each air sampling quartz filter was heated at $120^{\circ} \mathrm{C}(\mathrm{OC} 1), 250^{\circ} \mathrm{C}(\mathrm{OC} 2), 450^{\circ} \mathrm{C}(\mathrm{OC} 3)$, and $550^{\circ} \mathrm{C}(\mathrm{OC} 4)$ in a helium $(\mathrm{He})$ atmosphere, and then at $550^{\circ} \mathrm{C}(\mathrm{EC} 1), 700^{\circ} \mathrm{C}$

Table 1: Protocol of IMPROVE thermal / optical method for carbonaceous analysis.

\begin{tabular}{ccc}
\hline $\begin{array}{l}\text { Carbonaceous } \\
\text { fraction }\end{array}$ & $\begin{array}{r}\text { Temperature } \\
\left({ }^{\circ} \mathrm{C}\right)\end{array}$ & Atmosphere \\
\hline OC1 & 120 & \\
OC2 & 250 & $100 \% \mathrm{He}$ \\
OC3 & 450 & \\
OC4 & 550 & \\
\hline EC1 & 550 & $2 \% \mathrm{O}_{2}+98 \% \mathrm{He}$ \\
EC2 & 700 & \\
EC3 & 800 & \\
\hline
\end{tabular}


(EC2), and $800^{\circ} \mathrm{C}(\mathrm{EC} 3)$ in an oxidizing atmosphere of $2 \% \mathrm{O}_{2}$ and $98 \% \mathrm{He}$. The analysis was repeated two or three times for each air sampling quartz filter for better accuracy.

\subsubsection{Evaluation of ionic composition of SPM in the exhaust gases}

One fourth of $8 \mathrm{~mm}$ diameter Teflon filter was ultrasonically extracted with 50 $\mathrm{mL}$ ultrapure water (18.2M $\Omega$ milli-Q water ) for 20 minutes, in order to carry the ionic composition analysis of anions $\left(\mathrm{NO}_{3}{ }^{-}, \mathrm{SO}_{4}{ }^{2-}\right.$, and $\left.\mathrm{Cl}^{-}\right)$and cations $\left(\mathrm{K}^{+}, \mathrm{Na}^{+}\right.$, $\mathrm{NH}_{4}^{+}$, and $\mathrm{Ca}^{2+}$ ), respectively. All extracts were analyzed using an ion chromatograph (Dionex-100 IC, Japan Dionex Co., Tokyo, Japan) equipped with an electric conductivity detector. Mixed standards of five concentrations within the ranges of 0.1-2.5 ppm (w/v) for anions and 0.05-0.8 ppm (w/v) for cations were used to draw standard calibration curves. The analysis was also repeated two times for each air sampling quartz filter for better accuracy.

\section{Results and discussions}

\subsection{Measurements in the composition of the rice husk}

In table 2 are shown the composition analysis for the waste rice husk samples from different producing areas. Regarding the residual ash contents of the waste rice husk slightly below $20 \%$ in mass, it was supposed that the waste rice husk is one kind of low-grade fuels, and it should be difficultly to be widely used as fuel [8].

Table 2: Composition analysis of rice husk samples from different producing areas (names of farm or brand).

\begin{tabular}{lccccccc}
\hline $\begin{array}{l}\text { Producing areas } \\
\text { Farm (brand) }\end{array}$ & Ash (wt\%) & $\begin{array}{c}\mathrm{M} \\
(\mathrm{wt} \%)\end{array}$ & $\begin{array}{c}\mathrm{VM} \\
(\mathrm{wt} \%)\end{array}$ & $\mathrm{FC}(\mathrm{wt} \%)$ & $\mathrm{C}(\%)$ & $\mathrm{H}(\%)$ & $\mathrm{N}(\%)$ \\
\hline $\begin{array}{l}\text { Miyazaki } \\
\text { (Koshihikari) }\end{array}$ & 14.3 & 9.9 & 61.3 & 14.6 & 38.7 & 5.1 & 0.4 \\
Kirari Miyazaki & 13.3 & 10.0 & 61.9 & 14.8 & 39.0 & 5.1 & 0.3 \\
Niigata & 18.9 & 8.4 & 58.2 & 14.5 & 37.4 & 4.7 & 0.3 \\
Hokkaido & 16.7 & 9.7 & 60.9 & 12.7 & 39.2 & 5.1 & 0.5 \\
Saitama & 18.4 & 6.70 & 60.0 & 14.9 & 38.8 & 5.1 & 0.4 \\
Hokkaido & 19.2 & 7.6 & 59.2 & 14.0 & 37.9 & 5.1 & 0.5 \\
(Hoshinoyume) & 19.2 & & & & & &
\end{tabular}

M: Moisture, VM: Volatile matter and FC: Fixed carbon.

\subsection{Differential combustion characteristics of the different rice husk samples}

The thermogram for Miyazaki rice husk (Koshihikari) showed two well-defined peaks of TG/DTA at $320^{\circ} \mathrm{C}$ and around $400^{\circ} \mathrm{C}$ (figure 3 ). These results show that 
this kind of waste rice husk achieves its pyrolysis around $320^{\circ} \mathrm{C}$, where the more volatile components are burned and the carbonized fraction is burned at a higher temperature, around $400^{\circ} \mathrm{C}$. This combustion behavior was also confirmed for the other three kinds of rice husk with the peak differences around 20 to $50^{\circ} \mathrm{C}$ between the different waste rice husk samples produced from various areas (farms or brand).
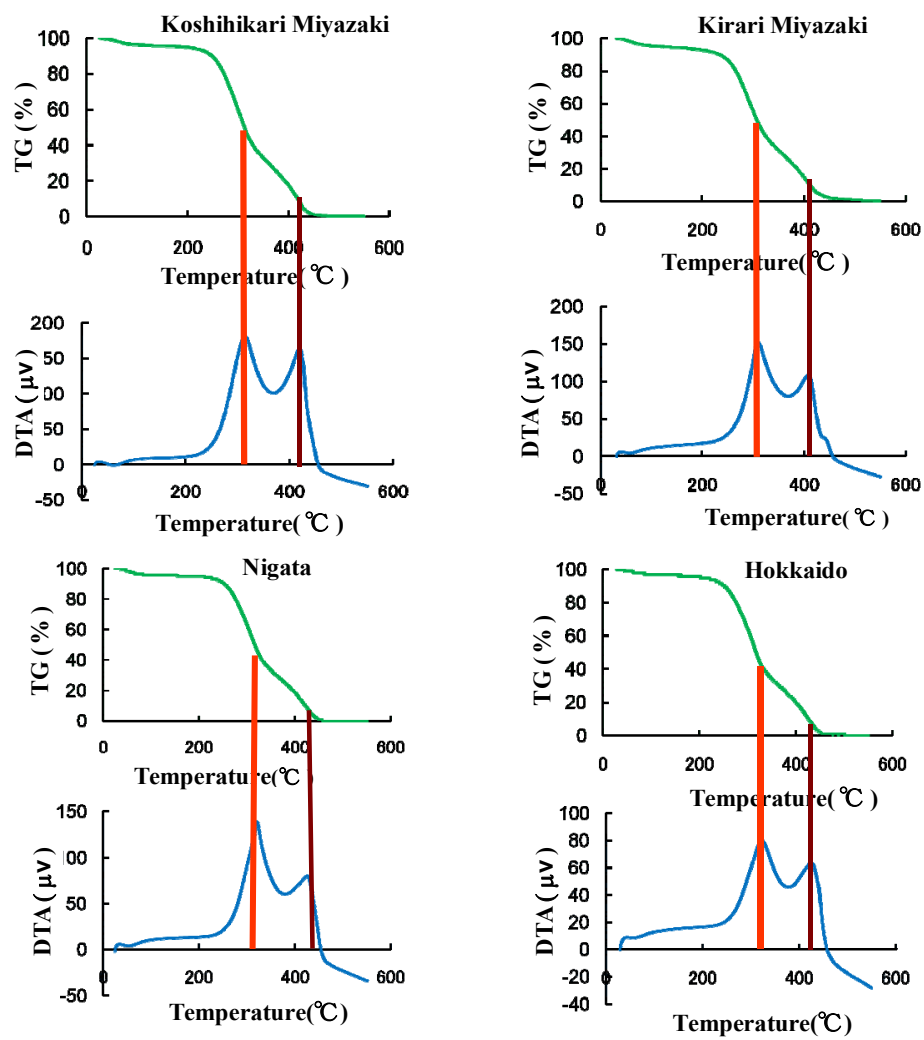

Figure 3: Combustion and pyrolysis behavior of rice husk samples.

\subsection{Temperature control for the new-type combustor of waste rice husk}

In order to reach stabilization in the combustor temperature, the combustor was first heated with the oil burner until the temperature of $550{ }^{\circ} \mathrm{C}$ was reached, then the rice husk was fed into the combustor which made the temperature to change. After that, it is waited for the stabilized temperature until about $800{ }^{\circ} \mathrm{C}$ in the outer wall and/or about $1,000{ }^{\circ} \mathrm{C}$ in the inside of the combustor. Figure 4 shows the variation of the temperature profiles in the outer wall and the inside of combustor and surrounding air in the room. Temperature in the inside of the combustor is stabilized around $970{ }^{\circ} \mathrm{C}$, which is the well-known temperature condition that the harmful substances such as dioxins can be extremely reduced. 
In addition, if temperature is controlled at those levels, the generation of thermalNOx can also be controlled because thermal-NOx is generated at temperatures above $1,100^{\circ} \mathrm{C}$. The combustion temperature and the heating energy provided by this new-type combustor is enough for the intended purpose, additionally, it can be achieved with trace levels of harmful substances and less NOx emissions.

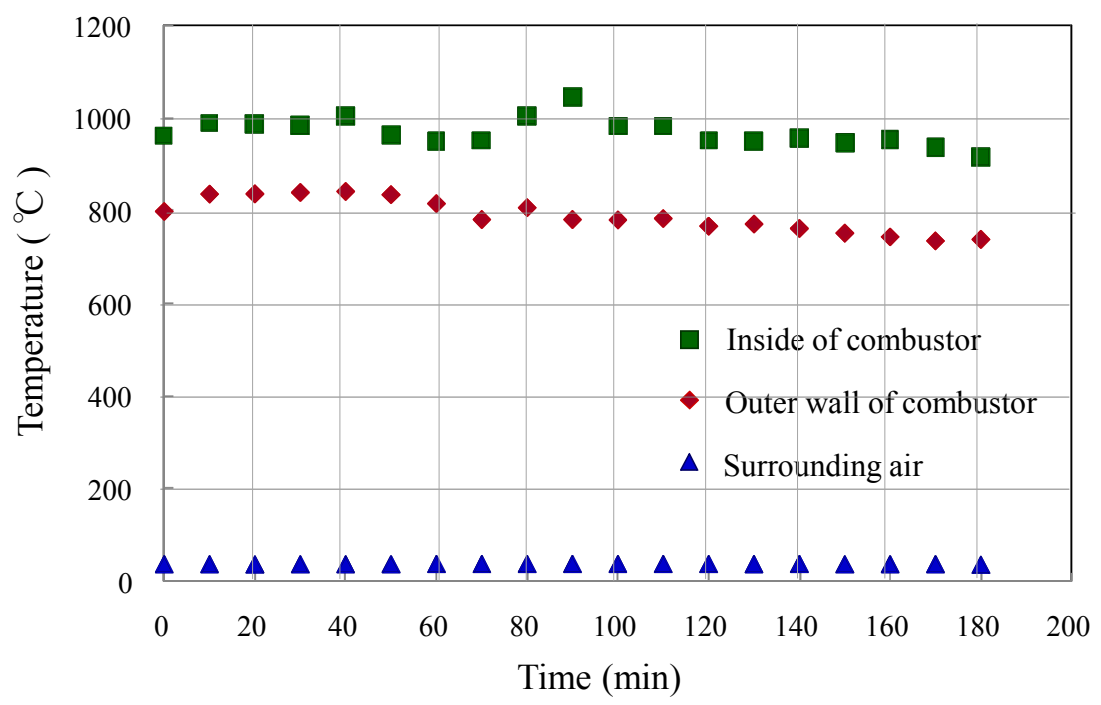

Figure 4: Temperature profiles in the inside and outer wall of the combustor and surrounding air during analysis.

\subsection{Evaluation of exhaust gases from the new small scale combustor}

\subsubsection{Emission behavior of carbonaceous composition of SPM in the exhaust gases}

The analytical results of carbonaceous composition of suspended particulate matter (SPM) in the exhaust gases are shown in figure 5. EC1 which is mainly generated by biomass burning (combustion) at relatively lower temperatures was found at the highest concentrations in the particle sizes from 1.2-2.1 $\mu \mathrm{m}$ to 2.1$3.5 \mu \mathrm{m}$ as the coarse particles. OC4 was also determined at the high levels in fine particles $(1.2-2.1 \mu \mathrm{m})$ and coarse particles. From these results, we can conclude that these combustion conditions of the waste rice husk may also be under incomplete combustion. OC2 includes compounds like levoglucosan and methoxyphenol, which are generated in the pyrolysis of cellulose and lignin, was found at the highest concentrations in the particle sizes below $1.2 \mu \mathrm{m}$ as the fine particles; levoglucosan is one of the water-soluble organic carbonaceous components and it can contribute to cloud condensation nuclei, and influence on the global warming and climate by the optical properties of such kind of carbonaceous aerosol $[9,10]$. 


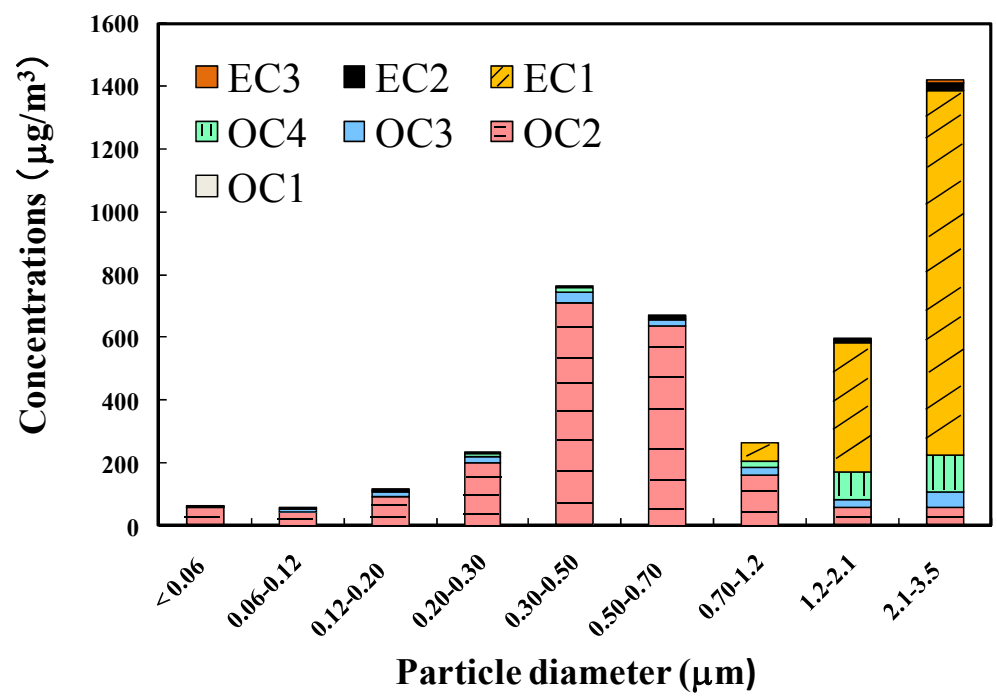

Figure 5: Size distribution of organic and elemental carbon composition in exhaust gases.

We consider that in this experiment, the air sampling method for atmospheric aerosol is not able to measure those semi-volatile carbonaceous components which would condensate from gases to particles by partition under cooling down to ambient temperature, and hence the real contribution to atmospheric aerosol may be underestimated. It is necessary to carry out experiments with an improved the air sampling method for the exhaust gases after air dilution in order to cool the exhaust gases down and have a better measurement of the real contribution of the semi-volatile carbonaceous components in the exhaust gases to atmospheric aerosol.

\subsubsection{Emission behavior of ionic composition of SPM in the exhaust gases}

The analytical results of ionic composition of suspended particulate matter (SPM) in the exhaust gases are shown in figure 6. Ionic concentration results showed that $\mathrm{K}^{+}$had a high concentration in all particle sizes. $\mathrm{K}^{+}$is an important component of biomass burning [11], since it is used in metabolic growth processes, hence this component is used as a marker for biomass burning (combustion) contribution to atmospheric aerosol. In addition, $\mathrm{Cl}^{-}$also showed high concentration in the all particle sizes from combustion of the waste rice husk. Because $\mathrm{Cl}^{-}$is especially found at higher concentrations during winter seasons; therefore, it is thought to arise from biomass burning of agricultural wastes including waste rice husk. In our further study, we plan to carry out combustion experiments using different biomass fuels, apart from waste rice husk in order to compare the abundance of $\mathrm{Cl}^{-}$from biomass burning of different agricultural wastes. 


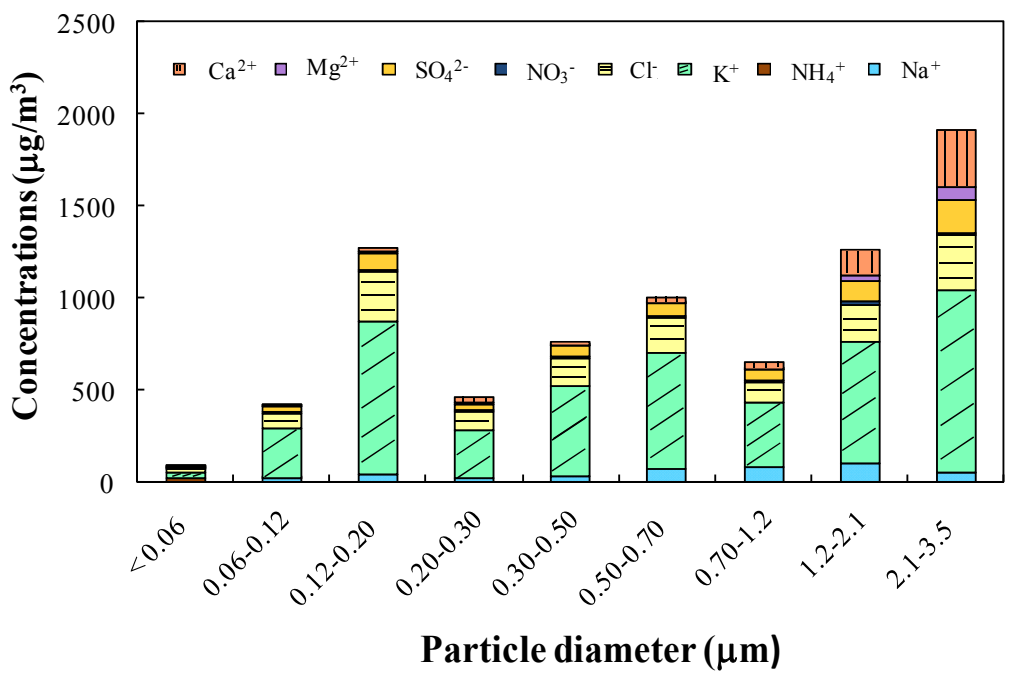

Figure 6: Size distribution of ionic components in exhaust gases.

\section{Conclusion}

In our experiments, we evaluated the combustion characteristics of the size distribution of exhaust particles (SPM) when using the several kinds of waste rice husk samples from different producing areas as the biomass fuel used for the new-type air vortex current combustor developed by our laboratories. The waste rice husk was suitable to maintain a combustion temperature above $800^{\circ} \mathrm{C}$. Our results indicate that waste rice husk is able to substitute fossil fuels if we use this new-type combustor.

From the analytical results of the size distribution of carbonaceous composition collected by the air sampling system, it is shown that elemental carbon (EC1) dominated in the coarse particles, which are produced by incomplete combustion, and organic carbon (OC2) dominated in the fine particles. Carbonaceous concentrations in the emitted particles can be reduced substantially by highly effective combustion when the combustion conditions of the combustor were improved. As the results of the ionic composition, high concentrations of potassium ion (a tracer of biomass burning) were determined. Combustion temperature control is important to avoid corrosion in the system and the health effects from high concentrations of chloride compounds (ions).

We also have to calculate the better air/fuel ratio in order to reduce the emission of harmful substances [12,13] and to optimize the fuel/carbon discharge coefficient in order to make the waste rice husk as a renewable energy source for alternate fossil oil fuel in the future. 


\section{Acknowledgements}

This study was supported by the Special Funds of the local Government of Saitama Prefecture, Japan, and partly subsidized by two Funds for Basic Researches (B) (No. 19404021, FY2007 FY2009 and No. 22404022, FY2010 2012) of Grant-in-Aid for Scientific Research of the Japanese Ministry of Education, Culture, Sports, Science and Technology (MEXT), Japan.

\section{References}

[1] A.A. Khan, W.de Jong, P.J. Jansens, H. Spliethoff., Biomass combustion in fluidized bed boilers: Potential problems and remedies., Fuel Processing Technology, 90, 21-50, 2009.

[2] Li Dong, Shiqiu Gao, Guangwen Xu., No reduction over Biomass Char in the Combustion Process., Energy Fuels, 24, 446-450, 2010.

[3] Lone A. Hansen, Hanne, P. Nielsen, Flemming J. Frandsen, Kim DamJohansen, Steffen Horlyck, Asger Karlsson., Influence of deposit formation on corrosion at a straw-fired boiler., Fuel Processing Technology, 64, 189-209, 2000.

[4] E.F. Iliopoulou, E.V. Antonakou, S.A. Karakoulia, I.A. Vasalos, A.A. Lappas, K.S. Triantafyllidis., Catalytic conversion of biomass pyrolysis products by mesoporous materials: Effect of steam stability and acidity of Al-MCM-41 catalysts, Journal of Chemical Engineering, 134, 51-57, 2007.

[5] L. S. Johansson, C. Tullin, B. Leckner, P. Sjovall., Particle emissions from biomass combustion in small combustors, Biomass and Bioenergy, 25, 435-446, 2003.

[6] Bernd R.T. Simoneit., Biomass burning-a review of organic tracers for smoke from incomplete combustion, Applied Geochemistry, 17, 129-162, 2002.

[7] Henrik Wiinikka, Rikard Gebart., Experimental investigation of the particle emissions from a small-scale pellets combustor, Biomass and Bioenergy, 27, 645-652, 2004.

[8] W. Permchart, V.I. Kouprianov., Emission performance and combustion efficiency of a conical fluidized-bed combustor firing various biomass fuels, Bioresource Technology, 92, 83-91, 2004.

[9] Jorger. Jimenez, Candiss. Claiborn, Ranils. Dhammapala, Christopherd. Simpson., Methoxyphenols and Levoglucosan Ratio in PM2.5 from Wheat and Kentucky Bluegrass Stubble Burning in Eastern Washington and Northern Idaho, Environment Science and Technology, 41, 7824-7829, 2007.

[10] Zhang Yuan-xun, Shao Min, Zhang Yuan-hangl, Zeng Li-min, He Ling-yan, Zyu-Bin, Wei Yong-jie, Zhu Xian-lei., Source profiles of particulate organic matters emitted from cereal straw burnings, Journal of Environmental Sciences, 19, 167-175, 2007.

[11] J. M. Jones, L. I. Darvell, T. G. Bridgeman, M. Pourkashanian, A. Williams., An investigation of the thermal and catalytic behavior of 
potassium in biomass combustion., Proceedings of the Combustion Institute, 31, 1955-1963, 2007.

[12] Q. Wang, P. Aparu, S. Nakamura, T. Maezono, I. Fujiwara and M. Domon, Evaluation of hybrid combustor of biomass and oil by vortex current of air, Research Report of Comprehensive Open Innovation Center of Saitama University, Japan, 2, 105-107, 2009 (in Japanese).

[13] I. Fujiwara and M. Domon, K. Morita, N. Yamaguchi, Q. Wang, T. Kumagai, Evaluation of hybrid combustor of biomass and oil by vortex current of air, Research Report of Saitama Industrial Technology Center, Japan, 8, 1-7, 2010 (in Japanese). 